\title{
Binding and transcriptional activation of the promoter for the neural cell adhesion molecule by $\mathrm{HoxC6}$ (Hox-3.3)
}

(homeobox/gene expression/morphogenesis/place-dependent signaling/N-CAM)

\author{
Frederick S. Jones*, Brent D. Holst*, Osamu Minowa*, Eddy M. De Robertis ${ }^{\dagger}$, \\ AND Gerald M. EdelmaN*
}

*Department of Neurobiology, The Scripps Research Institute, 10666 North Torrey Pines Road, La Jolla, CA 92037; and ${ }^{\dagger}$ Department of Biological Chemistry, University of California School of Medicine, Los Angeles, CA 92004

Contributed by Gerald M. Edelman, April 19, 1993

\begin{abstract}
Scores of homeobox gene-encoded transcription factors are expressed in a definite spatiotemporal pattern during embryogenesis and regulate a series of as yet unidentified target genes to help coordinate the morphogenetic process. We have suggested that homeobox gene products modulate the expression of adhesion molecule genes and have shown in cotransfection experiments that the promoters for the neural cell adhesion molecule (N-CAM) and cytotactin/tenascin genes respond to cues from different homeobox-containing genes. In this study, we show that the HoxC6 (Hox-3.3)-encoded homeoprotein binds to a DNA sequence in the $\mathrm{N}$-CAM promoter CCTAATTATTAA, designated homeodomain binding site I (HBS-I). To test whether HoxC6 regulated N-CAM promoter activity, we cotransfected the Long and Short reading frame variants of Xenopus HoxC6 (CMV-HoxC6-L and CMVHoxC6-S) driven by the human cytomegalovirus (CMV) promoter together with a chloramphenicol acetyltransferase (CAT) reporter gene driven by the mouse $\mathrm{N}-\mathrm{CAM}$ promoter (N-CAM-Pro-CAT). Cotransfection of NIH 3T3 cells with either of the CMV-HoxC6 expression vectors stimulated N-CAM promoter-driven CAT expression. A 47-bp region from the N-CAM promoter that included HBS-I and an adjacent potential HBS, HBS-II, conferred HoxC6 regulation on a simian virus $\mathbf{4 0}$ minimal promoter. HBS-I was sufficient for transactivation of the minimal promoter by CMVHoxC6-S. However, transcriptional activation by CMVHoxC6- $L$ required both HBS-I and HBS-II, inasmuch as mutation of either HBS-I, HBS-II, or both motifs abolished the response. These studies suggest that HBS-I is a target site for binding and transcriptional control of the N-CAM promoter by homeoproteins, although accessory DNA sequences (such as HBS-II) may also be required. Together with previous studies, these results support the notion that $\mathrm{N}-\mathrm{CAM}$ gene expression may be controlled by different combinations of homeoproteins that appear in a place-dependent manner during embryogenesis.
\end{abstract}

One of the fundamental riddles of developmental biology is how cells are patterned into tissues and organs in a form characteristic of a given species. Although the ultimate constraints on morphogenesis are coded in the genome, many of the events that give an animal its characteristic shape are epigenetic. The fate of embryonic cells depends on their lineage, on the nature of the immediate environment, and on their potential associations with other cells $(1,2)$.

Homeobox genes and their protein products have been shown to be important in defining spatial domains of morphogenetic activity in the embryo (3). These transcriptional regulators contain the homeodomain, a helix-turn-helix motif

The publication costs of this article were defrayed in part by page charge payment. This article must therefore be hereby marked "advertisement" in accordance with 18 U.S.C. $\$ 1734$ solely to indicate this fact. characteristic of a number of DNA binding proteins (4). The DNA core sequence of homeodomain binding sites (HBSs) frequently contains the sequence TAAT $(5,6)$. Homeobox genes regulate each other in a definite hierarchical and anteroposterior order $(7,8)$. Only recently have potential target genes for homeobox gene product regulation been identified $(9,10)$.

To understand better the process of cell patterning during development, a connection must be made between local transcriptional regulatory programs and cell-surface modulation events that coordinate the interactions of cells in time and space. A number of cell and substrate adhesion molecules are expressed in dynamic place-dependent patterns during embryogenesis and regulate the primary cellular processes that shape the animal, such as migration, proliferation, and differentiation (11). We have suggested that homeobox genes control the expression level of the genes encoding such proteins $(10,12,13)$. Combinatorial interactions of these morphoregulatory molecules (14) would in turn regulate mechanical associations of cells, eventuating in tissue pattern and form (15).

Consistent with these ideas, we have provided evidence that promoters for cell and substrate adhesion molecule genes are targets for regulation by homeobox gene products. In cellular cotransfection experiments, we have shown that the level of neural cell adhesion molecule (N-CAM) gene promoter activity is modulated by different stoichiometric amounts of vectors driving the expression of two Xenopus Hox genes, HoxB9 and HoxB8 (Hox-2.5 and -2.4). HoxB9 was a potent activator of N-CAM promoter activity while $H o x B 8$ was an inhibitor. Base-pair substitutions made within the TAAT motifs of N-CAM promoter HBSs disrupted the ability of $H o x B 9$ to activate the N-CAM promoter (12). In a separate study, cotransfection of plasmids driving the expression of $E v x-1$, a murine homeobox gene similar to the even-skipped gene product of Drosophila, was found to stimulate promoter activity for the gene encoding cytotactin/ tenascin, an extracellular matrix protein. Deletion and mutation of a TRE/AP-1 motif, located $276 \mathrm{bp}$ upstream from the RNA start site abolished activation of the cytotactin promoter by $E v x-1$ (13).

In the present study, we describe binding and activation of the N-CAM promoter by homeodomain proteins encoded by the Xenopus HoxC6 (Hox-3.3) gene. HoxC6 was chosen because the expression patterns of HoxC6 and N-CAM overlap extensively during development of the nervous system and of chick feather buds (16). We found that the HoxC6 gene product binds to a specific HBS in the N-CAM promoter and that transfection of NIH 3T3 cells with HoxC6 activates N-CAM promoter activity. Combined with our previous

Abbreviations: CAT, chloramphenicol acetyltransferase; SV40, simian virus 40; CMV, cytomegalovirus; HBS, homeodomain binding site; N-CAM, neural cell adhesion molecule. 
results, these observations suggest that a variety of homeobox gene products may regulate $\mathrm{N}-\mathrm{CAM}$ gene expression and that some homeodomain proteins achieve their modulatory effects on the N-CAM promoter through direct binding of promoter sequences.

\section{MATERIALS AND METHODS}

A $\beta$-galactosidase-Xenopus HoxC6 fusion protein containing the open reading frame of the Short protein minus the first five amino acids was prepared as described $(17,18)$. Nuclear extracts were prepared by the method of Dignam et al. (19). Probes for gel-shift experiments were derived from the 47-bp HBS region located between positions -559 and -512 in the mouse N-CAM promoter $(13,20)$. The region contains two putative HBSs, designated HBS-I and HBS-II (13). Oligonucleotides were annealed and labeled with the Klenow fragment of DNA polymerase I and $\left[\alpha^{-32} \mathrm{P}\right] \mathrm{dCTP}(3000 \mathrm{Ci} /$ mmol; $1 \mathrm{Ci}=37 \mathrm{GBq}$ ) (DuPont/NEN). For DNA/protein binding reactions, either HoxC6 fusion protein or nuclear extract (1-7 $\mu \mathrm{g})$ was mixed with $3 \mu$ l of $7 \times$ binding buffer $(350$ mM Tris $\cdot \mathrm{HCl}$, pH 7.5/1.75 $\mathrm{M}$ sucrose/14 mM MgCl$/ 175 \mathrm{mM}$ $\mathrm{KCl} / 7 \mathrm{mM}$ dithiothreitol/35 $\mu \mathrm{g}$ of bovine serum albumin per $\mathrm{ml} / 3.5 \mathrm{mM}$ phenylmethylsulfonyl fluoride), $2 \mu \mathrm{l}$ of poly(dI$\mathrm{dC}$ ), and $5 \times 10^{4} \mathrm{cpm}$ of probe DNA in a final vol of $20 \mu \mathrm{l}$. Competitor oligonucleotides were added and samples were incubated at room temperature for $30 \mathrm{~min}$. Denatured sonicated salmon sperm DNA ( $1 \mu \mathrm{l}$ of $5 \mathrm{mg} / \mathrm{ml})$ was added and samples were incubated for an additional $15 \mathrm{~min}$. Samples were applied to $5.5 \%$ polyacrylamide gels in $0.5 \times$ TBE $(1 \times$ TBE $=90 \mathrm{mM}$ Tris $/ 64.6 \mathrm{mM}$ boric acid $/ 2.5 \mathrm{mM}$ EDTA, $\mathrm{pH}$ 8.3), and after electrophoresis the gels were dried and autoradiographëd.

Expression vectors containing two protein variants of Xenopus laevis HoxC6 were prepared in the human cytomegalovirus (CMV) promoter vector CMV2' as described (12). The plasmids were designated CMV-HoxC6-L and CMV-HoxC6-S, for the Long and Short proteins, respectively. The N-CAM promoter/reporter gene plasmid, N-CAM-Pro-CAT (CAT, chloramphenicol acetyltransferase), and HBS enhancer/simian virus 40 (SV40) minimal promoter reporter constructs have been described (12). NIH 3T3 fibroblasts were grown in Dulbecco's modified Eagle's medium with $10 \%$ (vol/vol) calf serum. Cells were transfected with $10 \mu \mathrm{g}$ of HoxC6 expression vector and $10 \mu \mathrm{g}$ of N-CAM-Pro-CAT or HBS enhancer/SV40 CAT reporter construct using the calcium phosphate method (21). In addition, $5 \mu \mathrm{g}$ of $\mathrm{CMV}-\beta$-galactosidase gene reporter plasmid DNA was cotransfected to provide an internal standard for transfection efficiency. Cells were harvested after $72 \mathrm{hr}$; extracts were prepared, assayed for $\beta$-galactosidase activity, and then assayed for CAT activity (22). The amount of cell extract used for CAT assays was normalized to $\beta$-galactosidase activity. Levels of CAT activity were quantitated from TLC plates on a PhosphorImager (Molecular Dynamics, Sunnyvale, CA).

\section{RESULTS}

LacZ-HoxC6 Fusion Protein Binds to N-CAM Promoter HBS-I. The $X$. laevis HoxC6 gene (previously designated Xenopus-Hox-3.3 and XlHbox-1) was the first homeoboxcontaining gene to be isolated from vertebrates (23). The gene has been renamed in accordance with the improved nomenclature for the Hox genes (24). Transcription of Xenopus Hox C6 is initiated from two separate promoters spaced $9 \mathrm{~kb}$ apart in the genome, producing two mRNA transcripts during early development, 2.2 and $1.8 \mathrm{~kb}$ long. These transcripts encode HoxC6-L and $-S$ protein variants, both of which contain a DNA binding homeodomain of the Antennapedia
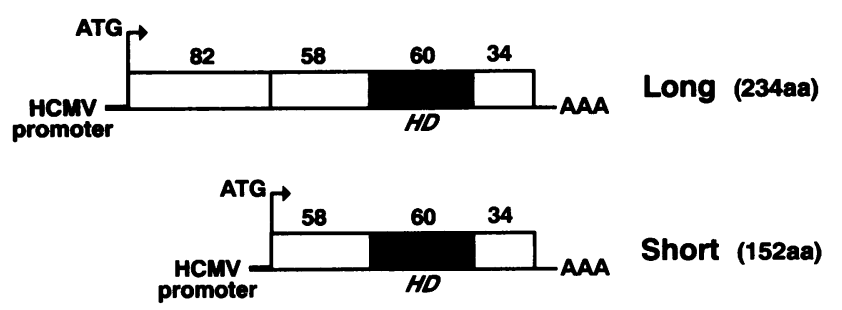

Fig. 1. Diagram of the two Xenopus HoxC6 variants and expression vectors. Expression of both variants is driven by the human (H) CMV promoter. Protein-coding regions of HoxC6 cDNA (boxed segments) are preceded by a short segment of 5 ' leader sequence from the Xenopus $\beta$-globin gene (dark line preceding the ATG initiator). Both HoxC6 variants contain an Antennapedia class homeodomain (HD) (solid box) and segments of 34 amino acids $\mathrm{C}$-terminal and 58 amino acids $\mathrm{N}$-terminal to it. The long protein has an $\mathbf{N}$-terminal segment of $\mathbf{8 2}$ residues not found in the short variant.

class (17). Both proteins share the same reading frame but the Long protein contains an 82-amino acid $\mathrm{N}$-terminal domain not found in the Short protein (Fig. 1).

We found previously that a 47-bp segment of DNA, containing two TAAT motifs, designated HBS-I and HBS-II, and located upstream of the mouse N-CAM gene, mediated responsiveness of the N-CAM promoter to HoxB9 and HoxB8 (Hox-2.5 and Hox-2.4) gene products (12). Previous studies also showed that a LacZ-HoxC6-S fusion protein bound to the Xenopus HoxB7 (Hox-2.3) promoter (17), which contains the DNA sequence TAAT - a motif known to be the core of a number of homeodomain binding sites $(5,6)$.

To determine whether the N-CAM promoter could bind Hox gene products, we assayed the 47-bp HBS region for binding to the HoxC6-S fusion protein in gel-shift experiments. We observed a single shifted band when the doublestranded ${ }^{32} \mathrm{P}$-labeled HBS DNA probe was mixed with the HoxC6-S fusion protein and electrophoresed on a native polyacrylamide gel (Fig. $2 B$, lane 2 ). We then tested four double-stranded oligonucleotides for their ability to compete for HoxC6-S fusion protein binding to the ${ }^{32} \mathrm{P}-$-labeled HBS probe. Competitors included the wild-type 47-bp HBS region of the N-CAM promoter containing HBS-I and HBS-II (designated $\mathrm{HBS}-\mathrm{I}^{+} / \mathrm{II}^{+}$) or three different mutants with base-pair substitutions in the TAAT core sequences of either HBS-I (HBS-I $\left.{ }^{-} / \mathrm{II}^{+}\right)$, HBS-II $\left(\mathrm{HBS}^{+} \mathrm{I}^{+} / \mathrm{II}^{-}\right)$, or both sites (HBS-I $\mathrm{I}^{-} / \mathrm{II}^{-}$) (Fig. 2A). A 100-fold molar excess of the wild-type HBS DNA (HBS- $\mathrm{I}^{+} / \mathrm{II}^{+}$) competed effectively for binding to the labeled HBS probe; the band representing the DNA-protein complex disappeared almost completely (Fig. $2 B$, compare lane 3 to lane 2). Excess unlabeled $\mathrm{HBS}-\mathrm{I}^{-} / \mathrm{II}^{-}$ DNA, with mutations in both HBS-I and HBS-II, did not compete with the HBS probe for binding of the fusion protein (lane 5). The HBS $-\mathrm{I}^{+} / \mathrm{II}^{-}$DNA, containing a mutation in HBS-II, competed for HoxC6-S fusion protein binding to HBS (compare lane 6 to lane 2) although not as effectively as HBS-I ${ }^{+} / \mathrm{II}^{+}$DNA. The HBS-I- $/ \mathrm{II}^{+}$oligonucleotide, with a mutation in HBS-I, did not compete for HoxC6-S fusion protein binding to the probe (compare lane 5 to lane 2). Taken together, the binding and competition experiments suggest that the HoxC6-S fusion protein binds to the HBS-I motif in the N-CAM promoter.

To provide additional support of HBS-I binding to the HoxC6-S fusion protein, we examined binding of three tandem copies of the N-CAM HBS-I motif $\left(\right.$ HBS- $\left.{ }^{+} \times 3\right)$. A number of wild-type and mutant multimers of the HBS-I and HBS-II sites were used to provide competition. The multimers contained three copies of a 12-bp fragment with either the wild-type or mutant HBS-I or HBS-II sequence (see bottom of Fig. $2 A$ ) and were designated HBS-I ${ }^{+} \times 3$, HBS$\mathrm{II}^{+} \times 3, \mathrm{HBS}^{-} \mathrm{I}^{-} \times 3$, and $\mathrm{HBS}-\mathrm{II}^{-} \times 3$, respectively. When the 
A

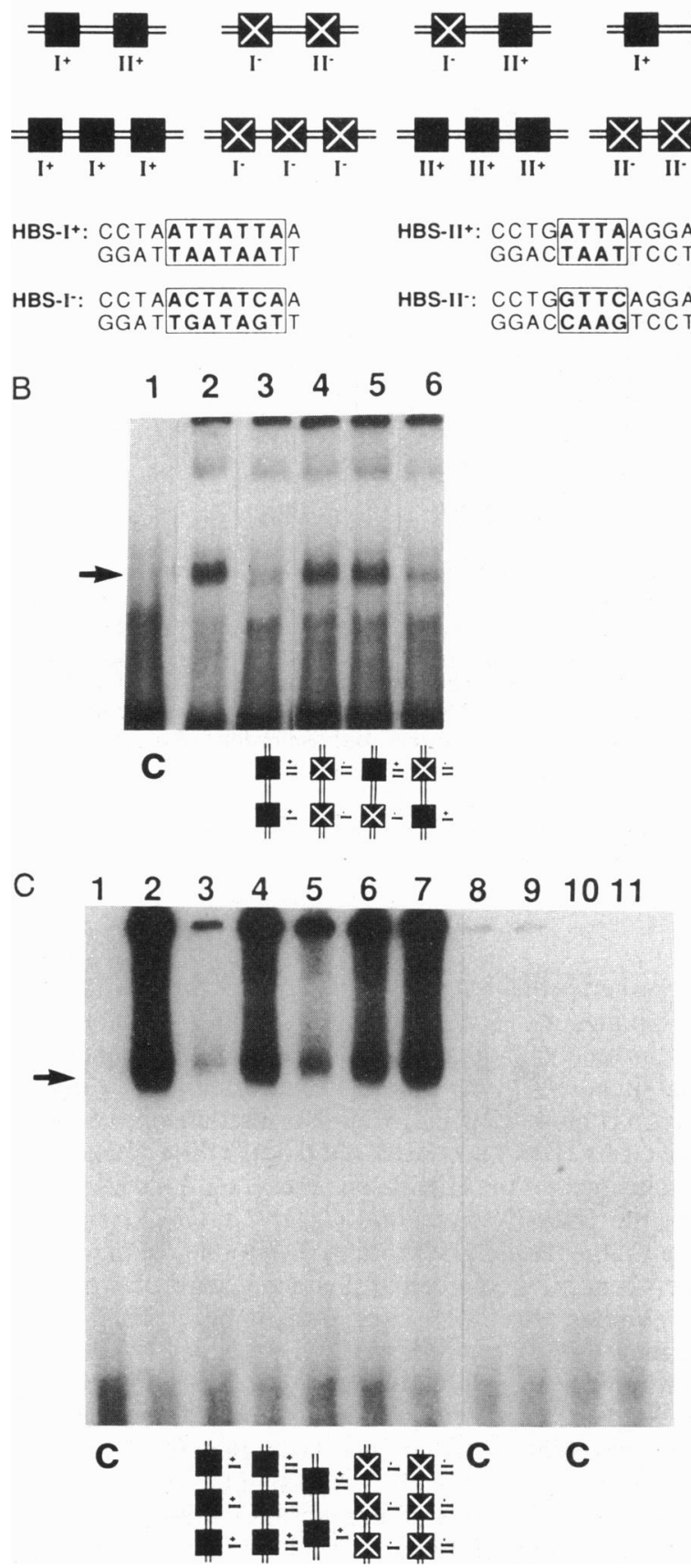

FIG. 2. (A) Schematic representation of the eight doublestranded oligonucleotides used in gel mobility-shift experiments. The two potential HBSs, HBS-I and HBS-II, from the N-CAM promoter are indicated by solid boxes. Mutants in the TAAT motifs are marked with an X. DNA sequences of the wild-type and mutant HBSs and the 12-bp segments repeated in synthetic HBS triplicates are shown below. (B) Binding of HoxC6 fusion protein to the 47-bp N-CAM HBS region. Autoradiograph of native polyacrylamide gel showing ${ }^{32} \mathrm{P}$-labeled HBS probe alone (lane 1) or binding to HoxC6-S fusion protein (lane 2). Competition of the HBS/HoxC6-S binding reaction was performed with the oligonucleotides indicated below each lane (lanes 3-6). (C) Binding of HoxC6-S fusion protein to HBS- $\mathrm{I}^{+} \times 3$. Autoradiograph of gel with ${ }^{32} \mathrm{P}$-labeled HBS-I $\mathrm{I}^{+} \times 3$ probe either alone (lane 1) or mixed with HoxC6-S fusion protein (lane 2). Competition of $\mathrm{HBS}_{-} \mathrm{I}^{+} \times 3 /$ HoxC6-S binding reaction was performed using the oligonucleotides specified below each lane (lanes 3-7). Binding reactions were also performed with ${ }^{32} \mathrm{P}$-labeled HBS$\mathrm{I}^{-} \times 3$ and $\mathrm{HBS}^{-\mathrm{II}^{-} \times 3}$ probes without (lanes 8 and 10 , respectively) or with (lanes 9 and 11, respectively) addition of HoxC6-S fusion protein.
HoxC6-S fusion protein was incubated with a ${ }^{32} \mathrm{P}$-labeled HBS $-\mathrm{I}^{+} \times 3$ DNA, we observed an intense band (Fig. $2 C$, lane 2 ; component indicated by arrow). The intensity of the band was reduced when a 50 -fold excess of unlabeled $\mathrm{HBS}^{-\mathrm{I}^{+}} \times 3$ was added to the binding reaction mixture as a competitor (compare lane 3 to lane 2), but it was not reduced by 50 -fold excess unlabeled $\mathrm{HBS}-\mathrm{II}^{+} \times 3$ (lane 4 ), $\mathrm{HBS}^{-} \mathrm{I}^{-} \times 3$ (lane 6 ), or HBS-II $^{-} \times 3$ (lane 7). Binding of HoxC6-S fusion protein to HBS $-\mathrm{I}^{+} \times 3$ was moderately blocked by competition with a 50 -fold excess of the native N-CAM HBS (compare lane 5 to lane 2). No binding of HoxC6-S fusion protein to ${ }^{32} \mathrm{P}$-labeled HBS-I ${ }^{-} \times 3$ or HBS-II $^{-} \times 3$ probes (lanes 9 and 11 , respectively) was observed.

Activation of N-CAM Promoter by HoxC6 in Cotransfection Experiments. To test whether the $\mathrm{Hox} C 6$ gene products could modulate N-CAM promoter activity, we first constructed vectors that would drive the expression of both the Long and Short variants (designated CMV-HoxC6-L and CMVHoxC6-S, respectively; see Fig. 1). We were able to detect both the long and short HoxC6 mRNA transcripts by RNase protection after transfection of these vectors in NIH 3T3 cells (data not shown). To determine whether the two HoxC6 expression vectors could produce proteins capable of binding the HBS-I motif, we tested nuclear extracts prepared from NIH 3T3 cells transfected with CMV-HoxC6-L and CMVHoxC6-S for binding to a ${ }^{32} \mathrm{P}$-labeled N-CAM promoter HBS- $\mathrm{I}^{+} \times 3$ probe. As shown in Fig. 3 , extracts from cells transfected with either CMV-HoxC6-L (lane 3), CMVHoxC6-S (lane 4), or an equal mixture of both vectors (lane 5) bound to the HBS- $\mathrm{I}^{+} \times 3$ sequence and produced a prominent band. This band was absent when nuclear extracts prepared from mock-transfected NIH 3T3 cells were used in the DNA binding reaction (lane 2).

To determine whether expression of HoxC6 variants in cells affected N-CAM promoter activity, we cotransfected the CMV-HoxC6-L and CMV-HoxC6-S plasmids in NIH $3 \mathrm{~T} 3$ cells together with the mouse N-CAM promoter/CAT gene reporter plasmid, N-CAM-Pro-CAT. Cotransfection of cells with either CMV-Hox C6-L or CMV-Hox C6-S plasmids induced CAT reporter gene expression driven by the N-CAM promoter (Fig. 4A). Cotransfection of the N-CAM-Pro-CAT construct with CMV-HoxC6-L produced 7.6-fold greater CAT activity than the background level produced by the vector control, pCAT basic, which had no N-CAM promoter sequences. Similarly, after cotransfection with CMVHoxC6-S, N-CAM-Pro-CAT yielded 6.8-fold greater CAT activity than pCAT basic. In the presence of an equal mixture

\section{$\begin{array}{lllll}1 & 2 & 3 & 4 & 5\end{array}$}

FIG. 3. Nuclear extracts prepared from NIH 3T3 cells transfected with HoxC6 expression vectors bind to $\mathrm{HBS}-\mathrm{I}^{+} \times 3$. ${ }^{32} \mathrm{P}-$ labeled $\mathrm{HBS}-\mathrm{I}^{+} \times 3$ probe (lane 1$)$ was incubated in binding reactions with nuclear extracts prepared from mock-transfected NIH 3T3 cells (lane 2) or from NIH 3T3 cells transfected with either $10 \mu \mathrm{g}$ of CMV-HoxC6-L (lane 3), $10 \mu \mathrm{g}$ of CMV-HoxC6-S (lane 4), or a mixture of $5 \mu \mathrm{g}$ of both vectors (lane 5). 

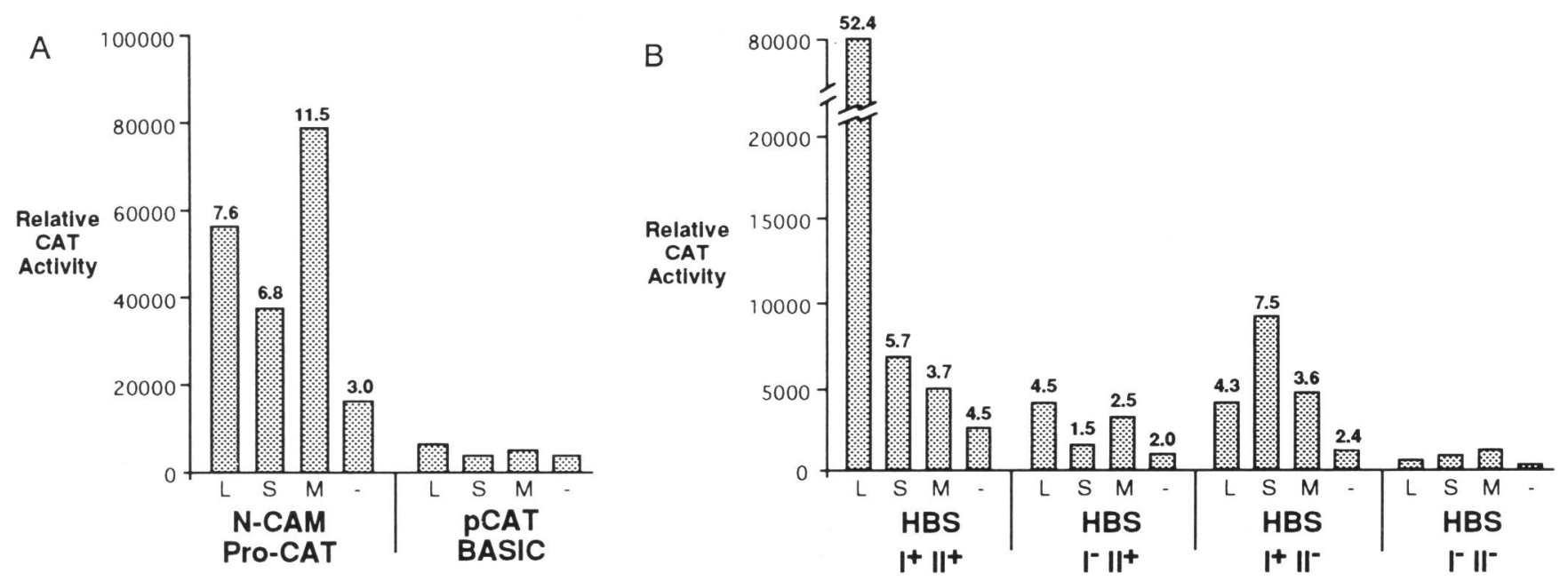

FIG. 4. Activation of CAT gene expression driven by the N-CAM promoter $(A)$ or the N-CAM HBS enhancer/SV40 minimal promoter $(B)$ constructs upon cotransfection with HoxC6 expression vectors. NIH 3T3 fibroblasts were cotransfected with $10 \mu \mathrm{g}$ of either pCAT basic, N-CAM-Pro-CAT, HBS-I ${ }^{+} / \mathrm{II}^{+}$, HBS-I $-/ \mathrm{II}^{+}, \mathrm{HBS}^{+} \mathrm{I}^{+} / \mathrm{II}^{-}$, and HBS-I- $/ \mathrm{II}^{-}$reporter vectors and $10 \mu \mathrm{g}$ of either CMV-HoxC6-L (L), CMV-HoxC6-S (S), an equal mixture containing $5 \mu \mathrm{g}$ of both vectors $(\mathrm{M})$, or no expression vector at all $(-)$. CAT activity levels were quantitated on a PhosphorImager (Molecular Dynamics) from scans of CAT assay samples applied to TLC plates. The degree of induction ( $n$-fold) is indicated over appropriate histograms and is derived from comparison of levels of CAT activity produced by N-CAM-Pro-CAT to levels produced by pCAT basic $(A)$ or levels of CAT activity produced by $\mathrm{HBS}-\mathrm{I}^{+} / \mathrm{II}^{+}, \mathrm{HBS}-\mathrm{I}^{-} / \mathrm{II}^{+}$, and $\mathrm{HBS}-\mathrm{I}^{+} / \mathrm{II}^{-}$reporters to those produced by $\mathrm{HBS}^{-} \mathrm{I}^{-} / \mathrm{II}^{-}$ $(B)$.

of both CMV-HoxC6-L and CMV-HoxC6-S, N-CAM-ProCAT had 11.5-fold greater activity than that produced from pCAT basic. In the absence of any HoxC6 expression vector N-CAM-Pro-CAT had only 3.0-fold higher CAT activity than pCAT basic (Fig. 4A).

To assess whether the HBS region of the N-CAM promoter was capable of mediating transcriptional activation by HoxC6, we tested reporter vectors containing wild-type and mutant HBS-I and HBS-II sequences for their ability to confer inducibility by HoxC6 to a SV40 minimal promoter in cotransfection experiments. As shown in Fig. 4B, cotransfection of CMV-HoxC6-L and CMV-HoxC6-S increased CAT activity from a reporter gene construct containing the wild-type HBS region $\left(\mathrm{HBS}-\mathrm{I}^{+} / \mathrm{II}^{+}\right) 52.4$-fold and 5.7-fold, respectively, over that produced by a reporter construct containing mutations in the TAAT motifs of both HBS-I and HBS-II (HBS-I- $\left.{ }^{-} / \mathrm{II}^{-}\right)$. In contrast to N-CAM-Pro-CAT, the HBS $-\mathrm{I}^{+} / \mathrm{II}^{+}$construct did not show a greatly elevated CAT activity when cotransfected with a mixture of the two HoxC6 expression plasmids (3.7-fold) (Fig. $4 B$ ). Thus, for the HBS$\mathrm{I}^{+} / \mathrm{II}^{+}$reporter construct, the presence of HoxC6-S seems to inhibit the much greater activation produced by HoxC6-L alone. A construct containing mutations of the TAAT motifs in both HBS-I and HBS-II (HBS- $\left.\mathrm{I}^{-} / \mathrm{II}^{-}\right)$showed no elevated CAT activity levels after cotransfection of HoxC6 expression plasmids. CAT activity from cells in which the $\mathrm{HBS}-\mathrm{I}^{+} / \mathrm{II}^{+}$ reporter had been cotransfected with CMV-HoxC6 plasmids was significantly higher than activity from cells that had not received the HoxC6 plasmids (Fig. 4, compare L, S, and M with -).

Experiments with reporter constructs containing mutations in either HBS-I or HBS-II were able to discern differences in the HBS motifs required for activation of promoter activity by the two variants of HoxC6. Cotransfection of cells with CMV-HoxC6-L and either HBS- $\mathrm{I}^{-} / \mathrm{II}^{+}, \mathrm{HBS}^{-} \mathrm{I}^{+} / \mathrm{II}^{-}$, or HBS-I- $/ \mathrm{II}^{-}$reporter constructs (with mutations in HBS-I, HBS-II, or both HBS-I and HBS-II, respectively) showed little, if any, increase in CAT activity (Fig. 4B). In contrast, cotransfection of cells with CMV-HoxC6-S showed a marked elevation in CAT activity driven by the $\mathrm{HBS}^{-\mathrm{I}^{+}} / \mathrm{II}^{-}$reporter (containing wild-type HBS-I and a mutated HBS-II motif) and no increase from $\mathrm{HBS}-\mathrm{I}^{-} / \mathrm{II}^{+}$or $\mathrm{HBS}-\mathrm{I}^{-} / \mathrm{II}^{-}$reporter vectors (containing mutations in HBS-I and both HBS-I and HBS-II, respectively).

\section{DISCUSSION}

Through a series of DNA mobility-shift experiments, we have shown binding of a HoxC6-S homeoprotein to a region of the $\mathrm{N}$-CAM promoter that contains two potential homeodomain binding sites. Wild-type HBS-I oligonucleotides competed for HoxC6-S binding, while HBS-II or mutants in the TAAT cores of either HBS-I and HBS-II did not. These data support the conclusion that the HBS-I sequence CCTAATTATTAA, and not the HBS-II sequence CCTGATTAGGA, mediates binding to the HoxC6-S protein. Components of nuclear extracts from NIH 3 T3 cells transfected with plasmids expressing either HoxC6-L, HoxC6-S, or both proteins also bound the N-CAM promoter HBS-I sequence, while those from untransfected cells did not.

We tested vectors driving the expression of Long and Short protein variants of the Xenopus HoxC6 gene for their ability to modulate activity of the N-CAM promoter. When cotransfected into NIH 3T3 cells, either variant stimulated N-CAM promoter activity. Mixture of the two variants yielded a greater induction of N-CAM promoter activity than did transfection with either variant alone. This result supports the notion that combinatorial expression of the HoxC6 variants has a synergistic effect on transactivation of the N-CAM promoter. During vertebrate development, both HoxC6 protein forms are expressed in the neural tube, although with different anterior borders of expression, at a time when $\mathrm{N}$-CAM is also expressed (18).

The HBS-I and HBS-II motifs were able to confer regulation by both HoxC6-L and HoxC6-S to a heterologous SV40 promoter. However, unlike the native N-CAM promoter, the synthetic reporter $\left(\mathrm{HBS}-\mathrm{I}^{+} / \mathrm{II}^{+}\right)$was unable to mediate the synergistic activation by the mixture of HoxC6-L and HoxC6-S. In fact, mixture of the two HoxC6 variants resulted in lower activation levels. These results suggest that HBS-I and HBS-II, when taken out of context, are not sufficient to reproduce the same responses to homeoproteins observed in the native promoter, and that other sequences in the N-CAM 
promoter may facilitate the synergy of activation normally observed.

We tested mutations in the TAAT motifs of HBS-I and HBS-II for their ability to mediate promoter activation by the HoxC6 variants. We found that HBS-I, the motif bound by the LacZ/HoxC6-S fusion protein in gel-shift experiments, was sufficient to confer activation of the minimal promoter by HoxC6-S and that mutation of HBS-II did not reduce activation. However, mutations in the TAAT motifs of either HBS-I, HBS-II, or both motifs abolished the ability of the HBS region to mediate activation by HoxC6-L. These data suggest that both HBS-I and HBS-II are required for regulation of promoter activity by $H o x C 6-L$, while activation by HoxC6-S requires only a single HBS-I motif. The 82-amino acid $N$-terminal domain of HoxC6- $L$ may engage in cooperative associations with other transcriptional regulatory proteins (which may include other homeoproteins) bound to accessory DNA sites at other locations in the promoter. HBS-II may be an example of such an accessory site. Such cooperative interactions and synergistic transcriptional regulation have been shown to occur between a variety of homeodomain proteins (25-27). The present results suggest that the Long and Short versions of $\operatorname{HoxC6}(17,28)$ can activate target genes differentially.

In a previous study using the same cotransfection system, we found that HBS-II mediated activation of the N-CAM promoter by HoxB9 (Hox-2.5) (12). Hence, HBS-I and HBS-II may mediate binding and transcriptional effects of different homeoproteins. Genes of the HoxB and HoxC (Hox-2 and Hox-3) clusters have been shown to be expressed in distinct regions in the dorsoventral axis of the developing neural tube and spinal cord $(29,30)$. Our results suggest that combinations of homeoproteins found at different positions in the embryo may determine appropriate levels of N-CAM gene expression during development.

In addition to the results of our studies, there is a growing body of evidence that also supports the idea that there is a tight link between homeotic gene function and cell adhesion. An immunoprecipitation strategy for uncovering chromatin actively bound by homeodomain protein in vivo (31) has recently revealed a regulatory region in the Drosophila connectin gene that is bound by the $U b x$ homeotic gene product (32). The connectin gene product has been shown to be a cell adhesion molecule (33). Mutations in the mab-5 gene, which encodes an Antennapedia class homeobox gene product in Caenorhabditis elegans, leads to abnormal neural pathfinding during development (34). Members of the $\mathrm{N}-\mathrm{CAM}$, cadherin, and integrin families of cell and substrate adhesion molecules have been implicated in cell axonal guidance phenomena in both invertebrate and vertebrate species $(11,35-38)$. Furthermore, it has been reported that uptake of an Antennapedia homeodomain peptide and the binding of target DNA sequences by primary cultures of neurons alters their morphology and neurite process extension properties $(39,40)$. In view of the accumulated evidence, it is an attractive hypothesis that a variety of cell and substrate adhesion molecules are targets for homeobox gene regulation during development. Different subsets of homeoproteins may be used for the many contexts of placedependent adhesion molecule gene expression $(15,41)$ during development. Such a diversity of transcriptional cues may be essential in local specification of neuronal migration pathways and tissue modeling.

We thank Dennis Bittner for the CMV-HoxC6 constructs, Eunice Huang and Doreen Chey for excellent technical assistance, and Julie Berlow for help in preparation of the manuscript. This work was supported by U.S. Public Health Service Grants HD09635, DK04256, and AG09326 to G.M.E., HD21502 to E.M.D.R., and a grant to G.M.E. from The Mathers Foundation.
1. Gurdon, J. B. (1987) Development 99, 285-306.

2. Edelman, G. M. (1988) Topobiology: An Introduction to Molecular Embryology (Basic Books, New York).

3. McGinnis, W. \& Krumlauf, R. (1992) Cell 68, 283-302.

4. Scott, M. P., Tamkun, J. W. \& Hartzell, G. W. (1989) Biochim. Biophys. Acta 989, 25-48.

5. Desplan, C., Theis, J. \& O'Farrell, P. H. (1988) Cell 54, 1081-1090.

6. Treisman, J., Harris, E. R. \& Desplan, C. (1992) BioEssays 14, 145-150.

7. Lewis, E. B. (1978) Nature (London) 276, 565-576.

8. Akam, M. (1989) Cell 57, 347-349.

9. Andrew, D. J. \& Scott, M. P. (1992) New Biol. 4, 5-15.

10. Edelman, G. M. \& Jones, F. S. (1992) Trends Biochem. Sci. 17, 228-232.

11. Edelman, G. M. \& Crossin, K. L. (1991) Annu. Rev. Biochem. 60, 155-190.

12. Jones, F. S., Prediger, E. A., Bittner, D. A., De Robertis, E. M. \& Edelman, G. M. (1992) Proc. Natl. Acad. Sci. USA 89, 2086-2090.

13. Jones, F. S., Chalepakis, G., Gruss, P. \& Edelman, G. M. (1992) Proc. Natl. Acad. Sci. USA 89, 2091-2095.

14. Edelman, G. M., Cunningham, B. A. \& Thiery, J. P., eds. (1990) Morphoregulatory Molecules (Wiley, New York).

15. Edelman, G. M. (1992) Dev. Dynamics 193, 2-10.

16. Chuong, C. M., Oliver, G., Ting, S. A., Jegaliam, B. G., Chen, H. M. \& De Robertis, E. M. (1990) Development 110, 10211030.

17. Cho, K. W. Y., Goetz, J., Wright, C. V. E., Fritz, A., Hardwicke, J. \& De Robertis, E. M. (1988) EMBO J. 7, 2139-2149.

18. Oliver, G., Wright, C. V. E., Hardwicke, J. \& De Robertis, E. M. (1988) EMBO J. 7, 3199-3209.

19. Dignam, J. D., Lebowitz, R. M. \& Roeder, R. G. (1983) Nucleic Acids Res. 11, 1475-1489.

20. Hirsch, M.-R., Gaugler, L., Deagostini-Bazin, H., Bally-Cuif, L. \& Goridis, C. (1990) Mol. Cell. Biol. 10, 1959-1968.

21. Ausubel, F. M., Brent, R., Kingston, R. E., Moore, D. D. \& Seidman, J. G., eds. (1989) Current Protocols in Molecular Biology (Wiley, New York).

22. Gorman, C. M., Moffat, L. F. \& Howard, B. H. (1982) Mol. Cell. Biol. 2, 1044-1051.

23. Carrasco, A. E., McGinnis, W., Gehring, W. J. \& De Robertis, E. M. (1984) Cell 37, 409-414.

24. Scott, M. D. (1992) Cell 71, 551-553.

25. Galang, C. K. \& Hauser, C. A. (1992) New Biol. 4, 558-568.

26. Han, K., Levine, M. S. \& Manley, J. L. (1989) Cell 56, 573-583.

27. Ananthan, J., Baker, R., Morrissey, D., Zuo, J., Lan, Y., Weir, M. \& Voellmy, R. (1993) Mol. Cell. Biol. 13, 1599-1609.

28. Wright, C. V. E., Cho, K. W. Y., Hardwicke, J., Collins, R. H. \& De Robertis, E. M. (1989) Cell 59, 81-93.

29. Gaunt, S. J., Coletta, P. L., Pravtcheva, D. \& Sharpe, P. T. (1990) Development 109, 329-339.

30. Graham, A., Maden, M. \& Krumlauf, R. (1991) Development 112, 255-264.

31. Gould, A. P., Brookman, J. J., Strutt, D. I. \& White, R. A. H. (1990) Nature (London) 348, 308-312.

32. Gould, A. P. \& White, R. A. H. (1992) Development 116, 1163-1174.

33. Nose, A., Mahajan, V. B. \& Goodman, C. S. (1992) Cell 70, 553-567.

34. Salser, S. J. \& Kenyon, C. (1992) Nature (London) 355, 255258.

35. Reichardt, L. F. \& Tomaselli, K. J. (1991) Annu. Rev. Neurosci. 14, 531-570.

36. Takeichi, M. (1991) Science 251, 1451-1455.

37. Hortsch, M. \& Goodman, C. S. (1991) Annu. Rev. Cell Biol. 7, 505-557.

38. Sonderegger, P. \& Rathjen, F. G. (1992) J. Cell Biol. 119, 1387-1394.

39. Joliot, A., Pernelle, C., Deagostini-Bazin, H. \& Prochiantz, A. (1991) Proc. Natl. Acad. Sci. USA 88, 1864-1868.

40. Bloch-Gallego, E., LeRoux, I., Joliot, A. H., Volovitch, M., Henderson, C. E. \& Prochiantz, A. (1993) J. Cell Biol. 120, 483-492.

41. Edelman, G. M. (1993) Cell Adhes. Commun., in press. 